\title{
Consultas populares: barreras institucionales y tensiones por la participación local
}

\author{
Recibido: 14 de abril de 2020 • Aprobado: 22 de mayo de 2020 \\ https://doi.org/10.22395/ojum.v20n4la3
}

\author{
Andrea Montoya Giraldo \\ Universidad de Antioquia, Medellín, Colombia \\ andrea.montoyag@udea.edu.co \\ https://orcid.org/0000-0001-6852-5944 \\ Johan Mauricio Villegas Murillo \\ Universidad de Antioquia, Medellín, Colombia \\ johan.villegasm@udea.edu.co \\ https://orcid.org/0000-0003-4190-4279
}

\section{RESUMEN}

Este artículo da cuenta de las controversias que se han suscitado en el plano jurídico y político en relación con la exploración y explotación minera en los municipios, y las barreras institucionales a las que se han visto enfrentados los ciudadanos en la utilización de este mecanismo de participación ciudadana en relación con temas mineros en los municipios de Pueblorrico (Antioquia), Cajamarca (Tolima) y Córdoba (Quindío). Para la construcción de los casos de estudio, se acudió al tipo de investigación cualitativa con enfoque sociojurídico y se utilizó la estrategia documental acompañada de visitas al territorio con aplicación de entrevistas a los actores involucrados en estos procesos, identificando que los ciudadanos efectivamente se enfrentaron a prácticas desplegadas desde lo institucional, que reflejan la vulneración de las garantías democráticas que el Estado tiene la obligación de proteger.

Palabras clave: participación ciudadana; participación ambiental; consulta popular; barreras institucionales; democracia. 


\section{Popular Consultations: Institutional Barriers and Tensions for Local Participation}

\section{ABSTRACT}

This article reports on the controversies that have arisen at the legal and political levels in relation to mining exploration and exploitation in the municipalities, and the institutional barriers that citizens have faced in the use of this mechanism of citizen participation in relation to mining issues in the municipalities of Pueblorrico (Antioquia), Cajamarca (Tolima) and Córdoba (Quindío). For the construction of the case studies, we used qualitative research with a socio-legal approach and a documentary strategy accompanied by visits to the territory with the application of interviews to the actors involved in these processes, identifying that the citizens effectively faced practices deployed from the institutional level, which reflect the violation of the democratic guarantees that the State has the obligation to protect.

Keywords: citizen participation; environmental participation; popular consultation; institutional barriers; democracy.

\section{Consultas populares: barreiras institucionais e tensões sobre a participação local}

\section{RESUMO}

Este artigo relata as controvérsias que surgiram em nível jurídico e político em relação à exploração e exploração mineira nos municípios, e as barreiras institucionais que os cidadãos têm enfrentado no uso deste mecanismo de participação cidadã em relação às questões de mineração nos municípios de Pueblorrico (Antioquia), Cajamarca (Tolima) e Córdoba (Quindío). Para a construção dos estudos de caso, utilizamos pesquisas qualitativas com uma abordagem sóciolegal e uma estratégia documental acompanhada de visitas ao território com a aplicação de entrevistas aos atores envolvidos nestes processos, identificando que os cidadãos efetivamente enfrentaram práticas implantadas a partir do nível institucional, que refletem a violação das garantias democráticas que o Estado tem a obrigação de proteger.

Palavras-chave: participação cidadã; participação ambiental; consulta popular; barreiras institucionais; democracia. 
¿Qué es un derecho fundamental en últimas? Si se me permite una definición casera yo diría que un derecho fundamental es la decisión política y moral que hemos tomado de respetar a una persona una libertad o una prestación así se caiga el mundo. La condición final de mi definición casera muestra la profunda dificultad del problema: tenemos que ser capaces de definir con toda responsabilidad, pero también con toda valentía, el conjunto de atribuciones, libertades, servicios y prerrogativas que, como sociedad estamos dispuestos a tolerar y financiar a toda costa. Tenemos también que ser capaces de definir que a quiénes han de beneficiar esos títulos jurídicos y cuándo y por qué hemos de establecer diferencias entre seres humanos.

(López, 2006)

\section{INTRODUCCIÓN}

Este artículo es resultado del proyecto de investigación Consultas populares: Barreras institucionales y disputas por la participación local, realizado en el marco de la convocatoria para proyectos de investigación presentados por estudiantes de pregrado de la Facultad de Derecho y Ciencias Políticas de la Universidad de Antioquia en 2018 y cofinanciado por el Programa de Semilleros de la Vicerrectoría de Investigación de la misma universidad.

La Constitución Política de 1991 definió la participación democrática como uno de los ejes axiales del ordenamiento constitucional colombiano, fundamento del poder político y uno de los fines del Estado. En otras palabras, la participación constituye un atributo del modelo constitucional adoptado y, en cuanto tal, tiene una serie de implicaciones entre las cuales se encuentra la consagración de una serie de mecanismos de participación, cada uno de los cuales supone distintos niveles de intervención ciudadana y diversos efectos jurídicos. La consulta popular es uno de los mecanismos de participación ciudadana directa, toda vez que por medio de esta se somete a votación del pueblo un determinado asunto de trascendencia nacional, departamental o local. Luego de la votación ciudadana, se deriva la obligatoriedad de implementación de la decisión por parte de la corporación pública del respectivo nivel (concejo, asamblea o congreso).

Dicho mecanismo ha adquirido gran relevancia nacional, y ha dado apertura a un fuerte debate constitucional alrededor de la distribución de competencias en el ordenamiento territorial ${ }^{1}$ desde el año 2013, cuando en el municipio de Piedras (Tolima) se convocó a los ciudadanos a decidir, mediante consulta popular, sobre la conveniencia o no de proyectos extractivos en el territorio. A partir de ese año, se impulsaron diecinueve consultas populares en todo el país en relación con la explotación minera en las localidades, y para el año 2018 había cincuenta y cuatro pendientes (González, 2018).

Al respecto se puede consultar: Osorio y Torres (2014) o Güiza y Rodríguez (2015). 
Según datos brindados por la Registraduría Nacional ante la Corte Constitucional en la Sentencia SU-095 (2018), entre los años 2013 a 2018 se votaron diez consultas populares en todo el país ${ }^{2}$, en las que un total de 73.297 personas se manifestaron en contra de las actividades extractivas sobre sus territorios. Sin embargo, la convocatoria de este mecanismo y el desarrollo de las consultas no estuvo exento de fuertes tensiones y controversias entre los distintos entes territoriales que resultaron en obstáculos y limitantes institucionales ${ }^{3}$ para su convocatoria y desarrollo. En algunos lugares donde se presentó esta iniciativa, como en los municipios de Pueblorrico y Córdoba, no se pudiera realizar. Por otro lado, en otros municipios donde se realizó, como es el caso de Cajamarca, los efectos jurídicos de estas decisiones están en entredicho, aun cuando al momento de realizar muchas de las consultas, el ordenamiento constitucional y legal vigente avalaba su realización $n^{4}$.

Teniendo en cuenta lo expuesto cabe preguntarse: ¿Cuáles son las barreras institucionales que se identifican en la ejecución de las consultas populares relacionadas con la minería para el ejercicio efectivo de la participación ciudadana en los municipios de Pueblo Rico (Antioquia), Cajamarca (Tolima) y Córdoba (Quindío)? Para responder a este pregunta, este escrito se divide en tres apartados en los que se presentan: i) las características, alcances y contenidos del derecho fundamental a la participación ciudadana y a la participación ambiental a la luz del ordenamiento jurídico colombiano; ii) la identificación y el marco normativo de las consultas populares como mecanismo de participación ciudadana en Colombia; y iii) la descripción de las barreras institucionales a las que se vieron enfrentados los ciudadanos de las localidades de Pueblorrico, Cajamarca y Córdoba, donde se convocó a este mecanismo de participación.

La elección de estos municipios obedece a que están ubicados en departamentos distintos, han tenido procesos sociales diversos y los fallos de los tribunales administrativos con respecto a la procedencia del mecanismo de participación ciudadana han sido diferentes. Esta diversidad permitió contrastar los procesos y analizarlos en su especificidad, sin pretender hacer un análisis comparativo de los mismos. Es importante mencionar que, aunque los resultados se circunscriben a contextos determinados, los resultados se pueden encuadrar en un marco amplio de análisis, como el fenómeno de la participación territorial en relación con proyectos mineros en Colombia, sin que con ello se desconozca sus especificidades (Galeano, 2004).

2 En los municipios de Carmen del Darién, Piedras, Tauramena, Cabrera, Cumaral, Pijao, Cajamarca, Arbeláez, Jesús María y Fusagasugá.

3 Esta situación fue ampliamente documentada en presa. Al respecto, se sugiere consultar El Espectador (2017) y Rubiano (2018).

4 Téngase en cuenta que la Corte Constitucional había establecido en la Sentencia T-445 (2016) que los municipios tenían la competencia para realizar estas consultas. Esta posición cambió en octubre de 2018 cuando se estableció que las consultas no eran el mecanismo procedente para oponerse a proyectos extractivos, y se ratificó en ello con la Sentencia C-053 (2019). 
Esta investigación fue de tipo cualitativo, de nivel descriptivo y con enfoque sociojurídico del derecho ${ }^{5}$. Se utilizaron estrategias y técnicas metodológicas complementarias: la estrategia documental acompañada de la revisión documental y las visitas al territorio ${ }^{6}$ con seguimiento en diario de campo y aplicación de entrevistas semiestructuradas a los actores involucrados ${ }^{7}$. Para ello, se desarrollaron tres etapas: i) la revisión bibliográfica de la normativa, jurisprudencia y literatura especializada sobre participación ciudadana y participación ambiental en relación con temas mineros; ii) la recolección de los documentos oficiales que dan cuenta de la realización del procedimiento establecido en la Ley Estatutaria 1757 (2015); iii) el análisis y la consolidación de la información. Se revisó, entonces, la exposición de motivos para la convocatoria de la consulta en cada localidad, los acuerdos municipales, las sentencias de los tribunales administrativos en su revisión oficiosa de la pregunta, las resoluciones de la Registraduría y los títulos mineros vigentes al momento de realizar esta investigación. Esta información fue obtenida mediante las visitas a las alcaldías de las localidades y la información publicada en las entidades oficiales, lo cual se complementó con un rastreo de prensa y la realización de entrevistas que dieron cuenta que tuvieron que enfrentar los ciudadanos en la convocatoria, desarrollo e implementación de este mecanismo de participación ciudadana.

\section{ALCANCE Y CONTENIDO DEL DERECHO FUNDAMENTAL A LA PARTICIPACIÓN CIUDADANA Y A LA PARTICIPACIÓN AMBIENTAL}

En el texto de la Constitución (1991) se establecen una serie de atributos al Estado social de derecho en el que se le asume como de carácter "democrático y participativo" (preámbulo, arts. 1 y 2). Estos atributos suponen un reconocimiento de una opción constitucional que contiene una serie de implicaciones y efectos respecto al origen, titularidad, ejercicio y control del poder político, toda vez que se le atribuye al pueblo la calidad de poder supremo o soberano y, en consecuencia, se reconoce que los ciudadanos tienen la posibilidad de intervenir en asuntos relacionados con la gestión

5 Este tipo de investigaciones se interesa en determinar cómo intervienen los sujetos, las instituciones y los discursos en la formación del saber donde sus fuentes son las propias realidades sociales, lo que permite al investigador analizar el estado de las cosas, el actuar de los sujetos y el análisis de los fines que se presentaron para regular o normalizar (Quintero et al., 2018).

6 El trabajo de campo posibilitó conocer de primera mano las características de los municipios, sus configuraciones y dinámicas sociales, y advertir un panorama más amplio con respecto a las formas de entender el territorio por parte de los actores y las visiones encontradas, acaso contradictorias, que se ciernen sobre los mismos.

7 Se consideró que los concejales eran actores clave para entender cómo se había realizado el procedimiento que, en su momento, tuvieron que avalar o no la realización de la consulta y fundamentar política y jurídicamente la procedibilidad del mecanismo, así como los grupos ciudadanos que la convocaron, porque a través de estos se indagó por el respeto a las facultades, atribuciones y contenidos del derecho a la participación ambiental. En total se realizaron ocho entrevistas de la cuales se dará cuenta en el apartado número tres del trabajo. 
pública y en los procesos decisorios que tienen incidencia en la orientación del Estado y la sociedad (Sentencia C-336, 1994).

Según lo han evidenciado Ramírez (2016), Echeverri (2011) y Velásquez y González (2003), el tránsito de la democracia representativa a la democracia participativa supone una complementariedad, ya que como resultado de la consagración de esta última se instauraron una serie de mecanismos e instrumentos jurídicos (el plebiscito, el referendo, la consulta popular, la iniciativa popular y el cabildo abierto). Estos mecanismos no solo permiten que los ciudadanos puedan elegir a sus gobernantes, sino decidir respecto de aquellos asuntos que los afectan directamente. Esto quiere decir que la expresión 'participativo' que utiliza el constituyente de 1991 va más allá de los atributos generales que ostenta cualquier democracia y alude a la presencia inmediata —no mediada — del pueblo en el ejercicio del poder público, ya como constituyente, legislador o administrador. En otras palabras, al concepto de democracia representativa se adiciona el de democracia de control y decisión. En esa medida, el tránsito a una democracia participativa supone que los ciudadanos no votan sólo para elegir, sino también para decidir (Sentencia C-150, 2015).

Teniendo en cuenta los pronunciamientos del Tribunal Constitucional, podemos advertir que el carácter de democracia participativa que asume la Constitución Política del 1991 reconoce: i) una forma determinada de funcionamiento y toma de decisiones (democracia como regla); ii) al pueblo como supremo soberano y titular del poder público (democracia como fuente de legitimidad); iii) la facultad de los ciudadanos no solo de conformar dicho poder político, sino de ejercerlo e intervenir directamente a través de una serie de mecanismos consagrados en la carta política (democracia como ejercicio); y iv) la posibilidad de controlar, vigilar, explorar y examinar la gestión de los órganos que expresan institucionalmente el poder público (democracia como control) (Sentencia C-179, 2002; Sentencia C-180, 1994; Sentencia C-150, 2015).

En Colombia, lo relacionado con las distintas dimensiones de la participación se encuentra consagrado en la Constitución Política de Colombia (1991, arts. 2, 3, 40, 103, 270, entre otros) y en las leyes estatutarias de participación ciudadana (Ley 134, 1994) de los mecanismos de participación ciudadana que fue modificada parcialmente por la Ley 1757 (2015). Con respecto a estas, el Tribunal Constitucional realizó control de constitucionalidad en las Sentencia C-180 (1994) y la Sentencia C-150 (2015).

Teniendo en cuenta este marco regulatorio y los pronunciamientos de la Corte Constitucional en sentencias (Sentencia C-180, 1994; Sentencia C-179, 2002; Sentencia C-150, 2015; Sentencia C-644, 2017), se pueden inferir una serie de características o atributos que hacen parte de este derecho que se reconoce a los ciudadanos, y que implican una serie de exigencias para el Estado en tanto le impone deberes de respeto, 
protección, garantía y aseguramiento ${ }^{8}$. En este trabajo se considera que no es dable reconocer que el derecho de participación solo se satisface con el cumplimiento de la obligación negativa de "no interferencia" por parte del Estado, toda vez que la efectiva tutela de este derecho exige garantías que implican la realización de conductas positivas por parte de las autoridades públicas. En este sentido, cuenta con obligaciones tales como disposición de fondos, prestación de servicios de vigilancia y seguridad, publicidad y transparencia, acceso a la administración de justicia, entre otros, los cuales son cometidos que suponen un mayor nivel de intervención.

En consecuencia, en la tabla 1 se describen los distintos niveles de protección que se derivan del derecho a la participación y las obligaciones que de ello resultan para las autoridades públicas, las cuales son características que devienen de lo consagrado en la Constitución Política y lo establecido por la Corte Constitucional en relación con el alcance de este derecho.

Tabla 1. Contenidos obligacionales del derecho a la participación ciudadana

\begin{tabular}{|c|c|c|c|}
\hline \multicolumn{4}{|c|}{ Contenidos obligacionales del derecho } \\
\hline Respetar & Proteger & Asegurar & Promover \\
\hline $\begin{array}{l}\text { El Estado debe abs- } \\
\text { tenerse de injerir, } \\
\text { obstaculizar o im- } \\
\text { pedir el acceso al } \\
\text { goce de los bienes } \\
\text { que constituyen el } \\
\text { objeto del derecho. }\end{array}$ & $\begin{array}{l}\text { El Estado tiene la obli- } \\
\text { gación de evitar toda } \\
\text { interferencia o coacción } \\
\text { de terceros respecto de } \\
\text { las libertades y derechos } \\
\text { protegidos. }\end{array}$ & $\begin{array}{l}\text { Se deben adoptar } \\
\text { medidas para que los } \\
\text { ciudadanos puedan ac- } \\
\text { ceder al bien protegido } \\
\text { por el derecho. } \\
\text { Según el Tribunal Cons- } \\
\text { titucional, el objeto } \\
\text { protegido se nutre de } \\
\text { todo aquello que pueda } \\
\text { interesarle a una persona } \\
\text { y al Estado, y que sea, } \\
\text { por tanto, susceptible } \\
\text { de afectar la distribución, } \\
\text { control y asignación del } \\
\text { poder social. }\end{array}$ & $\begin{array}{l}\text { El Estado debe de- } \\
\text { sarrollar condiciones } \\
\text { para que los titulares } \\
\text { del derecho accedan } \\
\text { al bien en el largo } \\
\text { plazo. }\end{array}$ \\
\hline
\end{tabular}

8 En términos de Abramovich y Courtis (2003), todos los derechos, llámense civiles, políticos, económicos o culturales tienen un costo y prescriben tanto obligaciones negativas como positivas. Los derechos civiles no se agotan en obligaciones de abstención por parte del Estado: exigen conductas positivas, tales como la reglamentación, el ejercicio del poder de policía, la protección frente a las interferencias ilícitas del propio Estado y de otros particulares y la eventual imposición de condenas por parte del Poder Judicial. 
Contenidos obligacionales del derecho

Frente a los deberes de abstención, que a su vez implican libertades para los ciudadanos, se tienen los siguientes:

i) No censura.

ii) Libertad de expresión.

iii) Libertad de asociación.

iv) Posibilidad de elegir y ser elegido.

v) No excesivo formalismo en las normas que regulan el ejercicio político.

vi) No exigencias desproporcionadas.
La protección que se debe brindar implica, según la Constitución Política (1991):

i) Que la participación realmente sea voluntaria (art. 16)

ii) Que las decisiones efectivamente sean expresión de las opciones personales (arts. 18 y 20).

iii) Que cada opinión sea igualmente valorada (arts. 13 y 14).

iv) Que los procedimientos fijados normativamente sean cumplidos (art. 29).

v) Que las distintas razones para justificar determinada decisión hayan sido debatidas, sopesadas y conocidas por la ciudadanía y que, además, las minorías hayan podido participar en dichos debates y sus derechos hayan sido respetados.
Respecto de la obligación de asegurar, el Estado debe:

i) Asumir los costos de la actividad electoral.

ii) Disponer los elementos necesarios para cumplir con dicha función.

iii) Prestar la seguridad y vigilancia debidas.

iv) Garantizar la transparencia.

v) Disponer de la administración de justicia frente a posibles desacuerdos

vi) Prestar vigilancia.
La garantía de protección a largo plazo en el derecho de participación se encuentra contenida en el alcance que le ha dado la Corte Constitucional a este como principio, en tanto ha establecido que tiene los atributos de expansividad y universalidad.

El principio democrático debe ampliarse progresivamente a nuevos ámbitos y hacerse cada vez más vigente: se reconoce como expansivo.

Y el principio universal compromete variados escenarios, procesos y lugares tanto públicos como privados.

Fuente: elaboración propia con base en la información de la Corte Constitucional (2019).

Es importante tener en cuenta que, con ocasión de instrumentos internacionales suscritos por Colombia ${ }^{9}$ y los diferentes procesos y litigios en los que se ha demandado la aplicación de la participación ${ }^{10}$, dicho derecho se ha venido ampliando y adquiriendo una connotación especial en el tema ambiental. En este sentido, se ha reconocido por parte de diversos instrumentos y en los pronunciamientos de los tribunales la necesidad de concebir la participación como garantía de involucramiento de las comunidades en la gestión de los ecosistemas, la protección de la diversidad ambiental y cultural y en la distribución de los recursos naturales, así como la asignación de cargas ambientales. Como bien lo establece Rodríguez (2009), la participación

9 La Declaración de Estocolmo de (Naciones Unidas, 1972), La Carta Mundial de la Naturaleza (Naciones Unidas, 1982), la Declaración de Río sobre Medioambiente (Naciones Unidas, 1992), el Protocolo de Kyoto sobre Cambio Climático (Naciones Unidas, 1997), el Acuerdo de París (Naciones Unidas, 2015), entre otros.

10 En las sentencias T-348 (2012), T-047 (2011), T-294 (2014), T-550 (2015), la Corte Constitucional encontró que más allá de si los demandantes eran parte o no de comunidades étnicas, les asistía el derecho de participación en las decisiones que los estaban afectando. 
ambiental cuenta con tres elementos indispensables, los cuales son i) el acceso a la información, ii) el acceso a la justicia y iii) el derecho a participar. Estos elementos implican que a los ciudadanos se les respete su posibilidad de ser escuchados, obtengan respuestas oportunas por parte de la Administración y se respete su derecho al debido proceso en el diseño, la instrumentación, el seguimiento, el monitoreo y la evaluación de las políticas, planes y programas establecidos en materia ambiental.

La Corte Constitucional ha sentado, vía precedente jurisprudencial, una serie de subreglas con respecto al contenido de la participación ambiental en las que se reconoce su carácter ius fundamental en relación con las actividades que comporten cambios en los ecosistemas y que sean susceptibles de vulnerar o afectar otros derechos fundamentales de los ciudadanos, tales como el derecho a un medio ambiente sano, el derecho al agua, el derecho al trabajo, el derecho a una vivienda digna, entre otros. En ese sentido, en la Sentencia T-361 (2017) ${ }^{11}$ se resumieron una serie de subreglas jurisprudenciales que determinan los alcances y contenidos a este derecho. Esta sentencia indica que la participación ambiental incluye elementos procedimentales y sustanciales necesarios para que exista una real y efectiva participación que debe agotar como mínimos las fases de a) convocatoria; b) información; c) consulta e iniciativa; d) concertación; e) decisión; f) gestión; y g) fiscalización. Esto significa que la gestión ambiental efectiva implica que los distintos actores intervengan con igualdad de oportunidades, y especialmente aquellos que son susceptibles de verse afectados en sus condiciones de vida por las decisiones que conllevan impactos en los ecosistemas.

En esa medida, cabe resaltar que en dicha sentencia se determina que la convocatoria debe ser amplia y abierta, y el proceso de deliberación debe respetar los principios de publicidad y contradicción de tal manera que se promueva un consenso razonado con la comunidad que permita un escenario de diálogo efectivo y significativo, el cual, en todo caso, no puede equipararse con la mera socialización. En otras palabras, para la Corte Constitucional, la participación no se agota con la socialización o la información, puesto que las autoridades al emitir la decisión deben tener en cuenta los argumentos esbozados en la deliberación, de tal manera que el acto administrativo evidencie que se evaluaron las razones de la comunidad y que se justificó su apartamiento (Sentencia T-348, 2012; Sentencia T-294 de 2014).

11 En esta sentencia, la Corte se pronunció sobre la delimitación del páramo de Santurbán y determinó el alcance de la participación ambiental de las comunidades respecto de este procedimiento. En esa medida, este constituye un precedente importante en la materia porque se refiere directamente a los atributos y alcance de la participación como derecho. De esta manera, se establece que los procedimientos administrativos que no tiene una regulación especial, como en el caso objeto de decisión de la Corte (lo que también sucede en los asuntos de concertación minera), deben prevalecer las reglas y principios constitucionales y los que se establecen en el Código de Procedimiento Administrativo y lo contencioso-administrativo. 
El derecho a la participación ambiental como evolución de la participación ciudadana ha tenido una serie de pronunciamientos jurisprudenciales que han ido acotando el contenido de este derecho en lo atinente al tema ambiental. Este ha sido reclamado por las comunidades en el tema minero-energético a través de la utilización de distintos mecanismos administrativos, como en el procedimiento de licenciamiento ambiental; mecanismos políticos como la consulta popular; y mecanismos judiciales en lo atinente a las diversas acciones constitucionales, especialmente la acción popular, la acción de tutela y la acción de inconstitucionalidad (Muñoz, 2016). Esto se suma al procedimiento de consulta previa derivado del Convenio 169 de la OIT (1989), el cual se reconoce como un derecho fundamental de las comunidades étnicas. En este sentido, comporta la obligación del Estado de efectuar un procedimiento de consulta que debe realizarse de buena fe y de una manera apropiada a las circunstancias, con el objetivo de llegar a un acuerdo o lograr el consentimiento acerca de las medidas propuestas (Rodríguez, 2014).

En cada uno de estos mecanismos, la consulta popular ha sido uno de los mecanismos que han utilizado los ciudadanos para expresar sus posiciones con respecto a la concesión de títulos mineros en sus territorios. Así, pone en el debate constitucional las competencias sobre el ordenamiento territorial de los municipios con respecto a las autoridades nacionales y a los alcances de este mecanismo de participación para decidir asuntos relacionados con la planificación territorial.

\section{MARCO JURÍDICO DEL MECANISMO DE PARTICIPACIÓN CIUDADANA DE LA CONSULTA POPULAR}

La Constitución Política (1991) reconoció los mecanismos de participación ciudadana en los artículos 103, 104 y 105 y desarrolló su contenido y reglamentación en la Ley 134 (1994) "Iplor la cual se dictan normas sobre mecanismos de participación ciudadana." Posteriormente, debido al carácter fundamental que ostenta el derecho de la participación, fue expedida la Ley Estatutaria 1757 (2015) "Iplor la cual se dictan disposiciones en materia de promoción y protección del derecho a la participación democrática".

Esta ley incluyó la posibilidad de convocar el mecanismo de la consulta popular por iniciativa ciudadana, es decir, quedó definido en el artículo 31 que el procedimiento para la convocatoria podía ser a través de iniciativa de alcalde, gobernador o presidente y que, además, un grupo significativo de ciudadanos (no menos del 10 \% del censo electoral) también podía elevar esta solicitud. En ambos casos, dicha petición primero debe surtir concepto favorable por la respectiva corporación pública (concejo, asamblea o congreso) y, posteriormente, una revisión ante el juez de lo contencioso-administrativo competente. Para el caso de los municipios, es el tribunal administrativo de la respectiva entidad territorial. 
Así, establecida la competencia del tribunal, hay dos los elementos clave que debe observar el Juez para determinar la procedencia del mecanismo. En este sentido, le corresponde:

i) Establecer si el asunto que se va a someter a la consulta popular es constitucional o no, teniendo en cuenta la normatividad aplicable, especialmente el artículo 18 de la Ley Estatutaria 1757 (2015), el cual de forma taxativa excluye la posibilidad de someter a votación determinadas materias.

ii) Una vez establecida la competencia, el tribunal debe pronunciarse sobre la legalidad de la pregunta teniendo en cuenta para ello la Sentencia C-551 (2003) de la Corte Constitucional, la cual precisó que reviste especial importancia la neutralidad de la pregunta formulada, ya que de esta manera se protege el derecho de libertad del elector de tal forma que en la pregunta no se vicie su juicio induciendo a una respuesta específica.

Una vez que se verifica la observancia de la normatividad, el tribunal debe declarar la constitucionalidad o no del mecanismo y de la pregunta. Finalmente, debe notificar a quien corresponda para que el proceso continúe y se pueda fijar la fecha de su realización o se suspenda el procedimiento.

Es importante precisar que en el tema específico de las consultas populares mineras se han dado una serie de pronunciamientos por parte de la Corte Constitucional y el Consejo de Estado. Por un lado, la sala cuarta de la contencioso-administrativo ${ }^{12}$ se ha pronunciado en sentido favorable, determinando que procede este mecanismo de participación para que los municipios prohíban actividades mineras en su jurisdicción. Esta posición se fundamentó en lo que dijo expresamente la Sala Plena de la Corte Constitucional en el auto A053 de 2017 al aclarar el alcance e interpretación de las sentencias T 445 de 2016 y C 123 de 2014.

Por su parte la Corte Constitucional, modificó lo dicho en las providencias antes mencionadas y determinó mediante la sentencia SU 095 de 2018 que a través de la Consulta Popular los municipios no podían prohibir la minería en sus territorios, concluyendo que este no era el mecanismo para decidir lo relativo a la explotación del subsuelo y por ello, a través de la sentencia mencionada cerró definitivamente la posibilidad de que los municipios convoquen a consultas populares, posición que reiteró en otras sentencias como la C 053 del 13 de febrero de 2019, en la que declaró inexequible el artículo 33 de la ley 136 de 1994 que fue el fundamento jurídico del cual se valieron los municipios para realizarlas.

Frente a la anterior decisión de la Corte Constitucional, aún sigue existiendo una disputa jurídica debido a que a la fecha en que se emitió dicho pronunciamiento, ya

12 Radicado 11001-03-15-000-2018-00083-01. 4 de octubre de 2018. M.P: Jorge Octavio Ramírez 
se habían celebrado 10 consultas siguiendo un procedimiento válido y vinculante y con un precedente (T 445 de 2016) que establecía que las autoridades municipales y ciudadanos efectivamente podían realizarlas.

En ese sentido, se puede concluir que las consultas populares con relación a temas minero-energéticos han sido declaradas no procedentes por el Tribunal Constitucional, al considerar que los municipios no tienen competencia para convocar a decisiones respecto de estos asuntos, sentencia que constituye un cambio de precedente.

Por ello, resulta de gran relevancia documentar los obstáculos a los que se han visto enfrentados los ciudadanos y las autoridades locales en la aplicación de este mecanismo de participación ciudadana. En su intento por disputarse con el nivel nacional la posibilidad de ordenar su territorio e incidir en la planificación de sus localidades, se han visto abocados a una serie de presiones y controversias que han terminado por restar eficacia a este mecanismo y por reducir el margen de posibilidad de expresión de los ciudadanos en asuntos que tienen implicaciones directas sobre sus modos de vida y en la forma misma en que se concibe el Estado.

\section{BARRERAS INSTITUCIONALES EN LOS CASOS DE PUEBLORRICO, CAJAMARCA Y CÓRDOBA}

\section{Concepto de barrera institucional}

Teniendo en cuenta que la pretensión de este trabajo es dar cuenta de las barreras institucionales que se identifican en la ejecución del mecanismo de la consulta popular, para efectos de esta investigación se define el concepto barrera como aquellos obstáculos que se dan en el ejercicio del derecho fundamental a la participación ciudadana. Estos ocurren cuando i) hay una intromisión injustificada al ejercicio del derecho mediante la regulación; ii) se genera un desconocimiento de los deberes de respetar, asegurar, proteger y promover por parte del Estado; y iii) se vulnera el alcance de universalidad y expansividad del principio de la participación inscrita en el modelo del Estado social de derecho. Los criterios que se utilizan para caracterizar lo que se considera "barrera" son de construcción propia, pero se apoyan en lo establecido por la Corte Constitucional respecto de los parámetros para hacer el estudio de la regulación que puede ser susceptible de afectar el ejercicio de los derechos fundamentales (Sentencia C-756, 2008).

Además de lo anterior, respecto del segundo y tercer criterio — bajo la posición doctrinaria a la que se adscribe este trabajo-, se entiende que el alcance del derecho a la participación debe interpretarse de acuerdo con un modelo de Estado que concibe la participación como constituyente de su forma de gobierno, lo cual se traduce en una serie de deberes y obligaciones para el Estado (tabla 2) que generan un desconocimiento del derecho cuando se incumplen. En otras palabras, toda intromisión injustificada a 
estos mínimos, así como la omisión en el cumplimiento de los deberes que se derivan para el Estado y los particulares, se tienen como vulneración del derecho.

Advirtiendo lo anterior, en este apartado se hace una reconstrucción de los procesos de convocatoria a consultas populares en los tres municipios señalados para poner en evidencia los obstáculos o barreras institucionales que se identificaron en estos. Aunque se reconocen particularidades en cada uno de ellos, en buena medida pueden retratar lo que ha sucedido en otros municipios del país en los que se plantearon discusiones y tensiones similares.

Tabla 2. Contexto de los municipios analizados

\begin{tabular}{|c|c|c|c|c|}
\hline Municipio & $\begin{array}{l}\text { Ubicación } \\
\text { geográfica }\end{array}$ & Economía & $\begin{array}{c}\text { Área de concesión } \\
\text { minera }\end{array}$ & Convocatoria consulta popular \\
\hline $\begin{array}{l}0 \\
.0 \\
0 \\
\frac{0}{0} \\
\frac{0}{2} \\
2\end{array}$ & $\begin{array}{l}\text { Suroeste } \\
\text { antioqueño. } \\
\text { Limita } \\
\text { con Tarso, } \\
\text { Jericó, } \\
\text { Andes, } \\
\text { Hispania, } \\
\text { Bolívar y } \\
\text { Salgar. }\end{array}$ & $\begin{array}{l}\text { Agrícola: café, } \\
\text { caña panelera } \\
\text { y plátano. }\end{array}$ & $\begin{array}{l}\text { Según datos de la } \\
\text { Agencia Nacional de } \\
\text { Minería }{ }^{13} \text { (s. f.) y de } \\
\text { la Gobernación de } \\
\text { Antioquia (2018), en } \\
\text { este municipio hay un } \\
\text { contrato con un área } \\
\text { de } 43.166 .120,5 \mathrm{~m}^{2} \\
\text { (adjudicada). También } \\
\text { hay tres propuestas } \\
\text { que están a la espera } \\
\text { de ser resueltas que } \\
\text { abarcan un área de } \\
\text { 10.306.120,21582 } \mathrm{m}^{2} .\end{array}$ & $\begin{array}{l}\text { 2015: El alcalde eleva solicitud } \\
\text { al Concejo Municipal. El Con- } \\
\text { cejo avala su realización y el } \\
\text { Tribunal Administrativo de An- } \\
\text { tioquia, la niega por considerar } \\
\text { que no tienen competencia las } \\
\text { autoridades locales. } \\
2017 \text { : El alcalde eleva nueva- } \\
\text { mente solicitud y el Tribunal } \\
\text { Administrativo de Antioquia } \\
\text { reconoce competencia de } \\
\text { acuerdo con el precedente de la } \\
\text { Corte, pero niega por considerar } \\
\text { que la pregunta estaba mal } \\
\text { formulada. }\end{array}$ \\
\hline 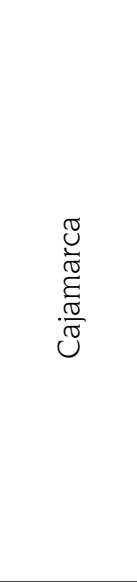 & $\begin{array}{l}\text { Municipio } \\
\text { del Tolima. } \\
\text { Limita al } \\
\text { norte con } \\
\text { Ibagué, al } \\
\text { sur con Ro- } \\
\text { vira y Ron- } \\
\text { cesvalles y } \\
\text { al occidente } \\
\text { con Salen- } \\
\text { to, Calarcá y } \\
\text { Pijao (Quin- } \\
\text { dío). }\end{array}$ & $\begin{array}{l}\text { Agrícola: Es } \\
\text { el principal } \\
\text { productor de } \\
\text { arracacha en el } \\
\text { país. Además, } \\
\text { produce hor- } \\
\text { talizas, café, } \\
\text { fríjol, arveja, } \\
\text { maíz, tomate } \\
\text { de árbol, etc. } \\
\text { Se le conoce } \\
\text { como despen- } \\
\text { sa agrícola de } \\
\text { Colombia. }\end{array}$ & $\begin{array}{l}\text { AngloGold Ashanti } \\
\text { consiguió seis títulos } \\
\text { mineros equivalentes } \\
\text { a } 15.220,66 \text { ha desti- } \\
\text { nadas a la explotación } \\
\text { de oro y minerales } \\
\text { como cobre, platina, } \\
\text { plata, zinc y molib- } \\
\text { deno } \\
\text { (Sentencia 11001-03- } \\
\text { 15-000-2016-03415- } \\
\text { 00, 2016). }\end{array}$ & $\begin{array}{l}\text { 2015: El alcalde eleva solicitud } \\
\text { al Concejo Municipal. El Conce- } \\
\text { jo no avala realización. } \\
\text { 2016: La ciudadanía logra reco- } \\
\text { lectar cuatro mil ochocientas } \\
\text { firmas, cumpliendo el requisito } \\
\text { para convocar este mecanismo. } \\
\text { En esta oportunidad, el Concejo } \\
\text { avala y el Tribunal Adminis- } \\
\text { trativo del Tolima encuentra } \\
\text { procedente la consulta. } \\
\text { 2017: Se realiza la consulta, con } \\
\text { la que obtienen } 6.165 \text { votos a } \\
\text { favor y } 76 \text { en contra }\end{array}$ \\
\hline
\end{tabular}

13 Para consultar las condiciones del título ingresar al Catastro Minero Nacional con el radicado HIDK-03 


\begin{tabular}{|c|c|c|c|c|}
\hline Municipio & $\begin{array}{l}\text { Ubicación } \\
\text { geográfica }\end{array}$ & Economía & $\begin{array}{c}\text { Área de concesión } \\
\text { minera }\end{array}$ & Convocatoria consulta popular \\
\hline 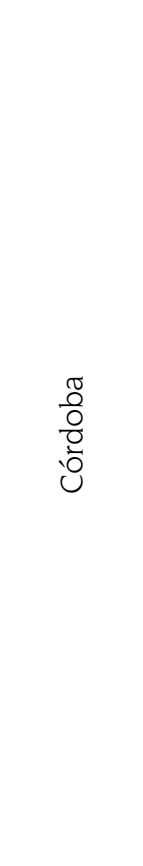 & $\begin{array}{l}\text { S u r d e l } \\
\text { Quindío. Li- } \\
\text { mita al norte } \\
\text { con el mu- } \\
\text { nicipio de } \\
\text { Calarcá, al } \\
\text { oriente con } \\
\text { Buenavista, } \\
\text { al sur con } \\
\text { Pijao y al oc- } \\
\text { cidente con } \\
\text { el Tolima. }\end{array}$ & $\begin{array}{l}\text { Agrícola y } \\
\text { ganadera. La } \\
\text { base de su } \\
\text { economía es } \\
\text { el cultivo de } \\
\text { café y plátano. }\end{array}$ & $\begin{array}{l}\text { Estudio de concesión } \\
\text { de } 1.626 \text { ha, comuni- } \\
\text { cado por la Agencia } \\
\text { Nacional de Minería } \\
\text { (El Tiempo, 2017). }\end{array}$ & $\begin{array}{l}\text { 2015: Se convoca a cabildo } \\
\text { abierto al que acuden ciento } \\
\text { veinte personas. } \\
\text { 2017: Alcalde eleva solicitud } \\
\text { al Concejo. El Concejo avala } \\
\text { realización. Se programa la } \\
\text { consulta. En noviembre del } \\
\text { mismo año la Registraduría pide } \\
\text { suspender la consulta debido a } \\
\text { que el Ministerio de Hacienda } \\
\text { no gira los recursos. } \\
\text { 2018: Alcaldía interpone acción } \\
\text { de tutela contra el Ministerio y } \\
\text { la Registraduría. Ministerio res- } \\
\text { ponde que es la localidad la que } \\
\text { debe financiar y la Registraduría } \\
\text { responde que no puede recibir } \\
\text { dinero de las localidades. } \\
\text { 2018: Controversia pendiente } \\
\text { de resolver por el Consejo de } \\
\text { Estado. }\end{array}$ \\
\hline
\end{tabular}

Fuente: elaboración propia.

\section{Descripción de las barreras institucionales de acuerdo con los deberes de respetar, proteger y asegurar que tiene el Estado}

Como se enunció en el primer apartado de este escrito, uno de los compromisos más importantes que tiene el Estado con el derecho a la participación es asegurar que las libertades de los ciudadanos puedan ejercerse sin que exista ninguna clase de intromisión por parte de las autoridades ni de particulares. Sin embargo, en el caso de las consultas populares se llevaron a cabo una serie de conductas que pueden catalogarse como un incumplimiento del deber de respeto:

\section{I) Comunicados que advierten con sanciones a funcionarios locales}

En el municipio del Pueblorrico se pudo observar que se contó con un apoyo general de los concejales y la administración municipal, lo cual facilitó el trámite de los debates que fueron abordados en esta instancia local y en su posterior votación en el Concejo. Sin embargo, según algunos integrantes del comité ambiental, luego de que los representantes de los órganos del nivel central (Procuraduría) se manifestaran diciendo, respecto de otras consulta populares, que los alcaldes se habían extralimitado en sus funciones (Gutiérrez, 2014) y que por ello se les iba a investigar, empezaron a generarse una serie de discusiones entre el colectivo socioambiental y la Alcaldía municipal, en 
tanto esta última fue dejando de pronunciarse respecto de esta materia. Con respecto a esta situación, el secretario del Concejo Municipal de Pueblorrico dijo:

ese era el temor también de los concejales cada que emitían algo: que desde lo nacional se les estaba diciendo que era una extralimitación de sus funciones y que podían ser sancionados. Esa también es la preocupación de los concejales, lo que los fue desanimando. (A.F. Pulgarín, comunicación personal, 15 de abril de 2019)

Estos comunicados de la Procuraduría implicaron, en su momento, mayor presión en Cajamarca, toda vez que esta entidad manifestó, respecto de la consulta promovida en la ciudad de Ibagué, que se iba a abrir investigación contra el alcalde de esta localidad, aunque para ese momento el Tribunal Administrativo del Tolima le hubiese dado vía libre al mecanismo de participación. Además, el ente disciplinario, en reunión con los concejales del municipio, les hizo saber que dicha competencia sobre la disposición de subsuelo solo estaba radicada en la nación ${ }^{14}$ :

Según el presidente del Concejo de Cajamarca, Camilo Andrés Padilla Zapata, la reunión en la Procuraduría General de la Nación fue con el objetivo de "advertir" a los cabildantes que el Ministerio Público investigará a todos los funcionarios que hayan promovido la consulta popular minera en el Tolima. (El Olfato, 2016)

Hincapié (2017) evidencia cuáles son los actores enfrentados en lo que ella denomina un nuevo ciclo de movilización social por la expansión de los derechos políticos, y se refiere a la Procuraduría como uno de los actores que, junto con el Gobierno central, defiende una tesis restrictiva de los mismos:

Considerando los antecedentes inmediatos ocurridos con los procesos iniciados en contra de las autoridades del municipio de Piedras, estas estrategias de presión ejercidas por la Procuraduría se constituyeron en fuertes desincentivos para las autoridades locales que apostaban por los procesos participativos. (p. 94)

De acuerdo con lo anterior, se evidencia que estos comunicados de la entidad disciplinaria implican una clara violación al deber de no interferencia en los asuntos de elección de los ciudadanos, sobre todo si se tiene en cuenta que, en el caso de Tolima, el Tribunal Administrativo había establecido en el control de constitucionalidad la procedibilidad de la consulta popular en Ibagué y mantuvo su posición respecto del municipio de Cajamarca. Esto quiere decir que, si bien resulta claro que una de las funciones de la Procuraduría es vigilar "el ejercicio de la autonomía y de los derechos de las entidades territoriales y promover las acciones pertinentes cuando se desborden los límites de la autonomía o se desconozcan los derechos de las entidades territoriales" (Decreto 262, 2000, art. 24), resulta exagerado que, en desarrollo de su función preventiva, la Procuraduría "advirtiera" sobre la vulneración al orden jurídico, diciendo que una las consecuencias de convocar a

14 Se debe tener en cuenta que para la fecha en que se convocó la consulta en este municipio, la Corte Constitucional ya había aclarado que los municipios debían participar de forma activa y eficaz en el proceso de toma de decisión (Sentencia C-123, 2014). 
este mecanismo era abrir investigaciones a alcaldes y concejales. A través de esta clase de actuaciones, estaría utilizando sus competencias disciplinarias para tratar de disuadir a los funcionarios locales de abstenerse de realizar consultas.

\section{II) Estigmatización}

Para efectos prácticos, es preciso hacer un acercamiento al significado del término estigma. Este concepto es empleado por Goffman (1963) en ciencias sociales, quien lo definió como "una marca, una señal, un atributo profundamente deshonroso y desacreditador que lleva a su poseedor de ser una persona normal a convertirse en alguien manchado" (p. 17). Estos elementos legitiman la exclusión moral de la sociedad de aquellos individuos que son considerados como diferentes.

Justamente, la defensa del territorio fue el elemento común de quienes fueron estigmatizados por diferentes actores, quienes veían en la participación de los distintos grupos sociales un obstáculo al modelo económico y al desarrollo proyectado. Sin embargo, esta no es una situación ajena al contexto del país ni mucho menos a las condiciones históricas a las cuales se enfrentan los líderes ambientales, ya que Colombia es el segundo país donde más se presentan asesinatos de estos líderes (Calle, 2019), es decir, frecuentemente son sometidos a señalamientos de toda clase que ponen en riesgo su integridad. Este panorama fue descrito por una integrante del Colectivo Socio Ambiental Juvenil de Cajamarca (Cosajuca) de la siguiente manera:

Ser líder social en este país es difícil por la estigmatización, porque entonces dicen: son de izquierda, son de la guerrilla, como la gente no tiene claro, son unos territorios muy marcados por una cultura muy conservadora, muy machista y el hecho de empezar a ver muchas mujeres en estos procesos, ¿qué hacen estas mujeres? (integrante del Colectivo Socio Ambiental Juvenil de Cajamarca [Cosajuca]-, comunicación personal, 21 de julio de 2019) ${ }^{15}$

La percepción es generalizada. Así se extrae de las declaraciones que hicieron otros líderes que participaron activamente en la defensa del territorio y en la consolidación de la consulta popular de Pueblorrico, quienes advirtieron similares consecuencias por pertenecer al colectivo:

Es evidente el señalamiento no solo por entidades estatales sino por entes no estatales, la participación no se concibe como que todo ciudadano tiene derecho a participar, ni como que nosotros estamos ayudando a cumplir los fines del Estado, eso nunca se ve de esa forma, se ve como un enemigo, un opositor, están en contra del desarrollo del municipio. (Y. González, comunicación personal, 13 de abril de 2019)

Situación similar se vivió en el municipio de Cajamarca, en donde también intervinieron actores que se opusieron a la causa de los grupos sociales que rechazaban la minería. Los líderes fueron señalados como "guerrilleros", lo que puso en riesgo

15 Por decisión personal del entrevistado, no se referencia su nombre. 
sus vidas a la par que la institucionalidad "negaba la publicidad, [...] los permisos de perifoneo, [...] nos echaba la policía, incluso la situación fue tan crítica que llegaban amenazas de las Águilas Negras" (integrante del grupo Semillas, comunicación personal, 14 julio de 2019) ${ }^{16}$.

Respecto del municipio de Córdoba existió mayor unanimidad en relación con la convocatoria a la consulta popular, y en esa medida los líderes sociales no manifestaron se hubiera presentado estigmatización hacia su labor.

Frente a esta barrera en específico, es importante señalar que aun cuando la consulta popular se instituyó como un mecanismo que pretendía la consolidación de los principios de la democracia participativa en la búsqueda de la convergencia entre las instituciones y la sociedad, la utilización de este mecanismo, más allá de ser considerada como una expresión legitima de democratización del Estado en muchos casos, fue vista como una acción que iba en contravía del progreso, lo que podría generar desempleo y desinterés de la inversión económica internacional.

\section{III) Límites financieros y disminución de mesas de votación}

Otro de los asuntos problemáticos en el desarrollo del mecanismo de participación involucró a la Registraduría Nacional del Estado Civil, institución que en muchas ocasiones anunció que no disponía de los recursos para el desarrollo de las consultas populares. En Córdoba, por ejemplo, se vivió tal situación, mientras que en Cajamarca, incluso cuando la consulta se realizó, no se asignaron las mesas de votación que correspondían al censo electoral.

Ello fue documentado por la prensa nacional. Se evidenció, entonces, que efectivamente existió un obstáculo financiero a las consultas populares por la tensión entre dos instituciones nacionales. Por una parte, la Registraduría señalaba al Ministerio de Hacienda de ser la entidad que debía financiar las consultas populares, mientras que esta cartera señalaba que el desembolso del presupuesto les correspondía a las entidades locales.

El Espectador publicó el 20 de mayo de 2018 una nota llamada Freno financiero a las consultas populares en la que evidenció, refiriéndose al caso del municipio de San Lorenzo (Nariño), que en carta dirigida al alcalde de la localidad, la Registraduría había recibido una negativa del Ministerio para financiar la consulta:

Sin embargo, en agosto del año pasado, ese Ministerio le respondió un derecho de petición a la Asociación Colombiana de Minería (ACM) y aseguraba que de su cartera no saldría un peso más para financiar consultas populares ni revocatorias de mandato. "Si el decreto de convocatoria para un comicio proviene de una entidad territorial, será responsabilidad de los alcaldes [...] la consecución de los recursos para garantizar esa jornada electoral", dice el documento, publicado por el diario Portafolio. (Rubiano, 2018)

16 Por decisión personal del entrevistado, no se referencia su nombre. 
Precisamente, se debe advertir que las respuestas del Ministerio y la Registraduría en el caso de Córdoba y otros municipios desconocen por completo el deber de asegurar el derecho fundamental a la participación, teniendo en cuenta que no solo se niega la disposición de los recursos necesarios para que los ciudadanos puedan ejercer su derecho a votar, sino que se desconoce el derecho a la igualdad. Mientras la respuesta para algunos municipios es que no hay recursos, para otros no se dio tal limitación y efectivamente la votación se surtió.

Ahora bien, estas decisiones de la Registraduría también se evidenciaron en la consulta popular de Cajamarca. Normalmente, en todos los comicios se dispone de treinta y cinco mesas de votación, pero para estas jornadas electorales solo se contó con dieciocho mesas, lo cual significa que habían alrededor de novecientos ochenta votantes por mesa, a lo que se sumó la disminución del tiempo de la jornada electoral:

Esta vez no sólo (sic) se reduce el número de mesas sino el tiempo que tienen los sufragantes para votar. Normalmente, las jornadas duran 11 horas, pero esta será de ocho. Según la Registraduría, ese horario cumple con lo establecido por la ley para las consultas populares. Sin embargo, de acuerdo con la Misión de Observación Electoral, ese factor podría generar congestión en las urnas y afectar la votación.

$[\ldots]$

A pesar de estas advertencias, la Registraduría decidió disminuir el número de mesas. Según la entidad, la razón principal de la medida es que el promedio de votantes en ocasiones anteriores ha sido muy bajo, por lo que no es necesario tener un número mayor de puestos. (Rolón, 2017, negrillas de la noticia)

También se reportaron otra clase de denuncias y videos, en los que los ciudadanos reclamaban que se estaban desplegando estrategias para que las personas no estuvieran en las votaciones:

A pocos días del evento, la tensión es evidente. Mientras que los promotores de la consulta hacen campaña por el 'No' en el pueblo y a través de las redes sociales, se han conocido denuncias sobre el supuesto interés de la empresa y de algunos políticos afines a ella de sabotear la participación ciudadana mediante estrategias como organizar viajes masivos y retener cédulas a cambio de dinero. Por si fuera poco, la Registraduría anunció esta semana que reducirá el número de mesas disponibles para votar, algo que los líderes de la consulta han tomado como un intento por evitar que la gente salga a votar. (Sostenibilidad Semana, 2017)

Al preguntar por estas situaciones en las entrevistas, los miembros de Cosajuca dieron cuenta de este acontecimiento de la siguiente manera:

La otra amenaza grande fue que la alcaldía les prometió viaje para San Andrés para mil ochocientas personas y la Basílica de Buga (para dos partes), que salían los buses a tales horas. Eso fue gravísimo para nosotros, nos pusieron en jaque, una votación de mil votos, eso se pierde. ¿Qué hicimos nosotros? Automáticamente 
hicimos comunicado y denunciamos ante la Procuraduría porque eso no debería ser, porque está en juego el territorio. (integrante del Colectivo Socio Ambiental Juvenil de Cajamarca [Cosajuca], comunicación personal, 21 de julio de 2019) ${ }^{17}$.

\section{IV) Costos para acceder a la información de expedientes mineros y reservas frente a información pública}

Como ya se mencionó en los apartados del derecho a la participación, uno de los asuntos más importantes para que este pueda realizarse de manera efectiva es que las comunidades y los actores involucrados en esta clase de procesos puedan conocer oportuna y debidamente la información que les interesa. Precisamente, en el Sistema Interamericano de Derechos Humanos (SIDH) se reconoce el acceso a la información pública como un derecho fundamental contemplado en el artículo 13 de la Convención Americana sobre Derechos Humanos (OEA, 1978), en el artículo 4 de la Carta Democrática Interamericana (OEA, 2001) y en el Acuerdo de Escazú (Cepal, 2018) que desarrolla el principio 10 de la Declaración de Río - aún pendiente de ratificación por Colombia - en el que se define la información ambiental como:

cualquier información escrita, visual, sonora, electrónica o registrada en cualquier otro formato, relativa al medio ambiente y sus elementos y a los recursos naturales, incluyendo aquella que esté relacionada con los riesgos ambientales y los posibles impactos adversos asociados que afecten o puedan afectar el medio ambiente y la salud, así como la relacionada con la protección y la gestión ambientales. (CEPAL, 2018, p, 25)

En relación con este tema, al indagar en las entrevistas se pudo evidenciar que en los procesos de concesión minera no existe ningún mecanismo para que los municipios y los ciudadanos participen en esta clase de $\operatorname{contratos}^{18}$ porque la autorización depende exclusivamente de entidades nacionales. Además, hay grandes obstáculos para que los ciudadanos conozcan esta información porque i) las entidades que tienen en su poder dichos expedientes o contratos se encuentran localizadas en Bogotá; ii) cobran por el acceso a los mismos; y iii) establecen una serie de reservas que no son de índole legal y que terminan haciendo nugatorio este derecho.

Sobre el particular, la Organización Tierra Digna (2019) expresó en su comunicado "10 principios a tener en cuenta para un ordenamiento socio ambiental del territorio desde el punto de vista del derecho a la participación" que el acceso a la información es una de las principales barreras en esta materia. En este sentido, advirtió que los contratos de concesión minera solo se encuentran en las instituciones de Bogotá, lo cual hace difícil que las personas de las localidades puedan acceder a ellos porque las distancias geográficas son considerables. Además, a esto se suma que el Estado y las

\footnotetext{
17 Por decisión personal del entrevistado, no se referencia su nombre.

18 Así lo estableció la Corte en la Sentencia SU-095 (2018).
} 
empresas se niegan a responder peticiones ${ }^{19} \mathrm{y}$ que para acceder a estos expedientes se cobran precios elevados que no pueden ser sufragados por las comunidades.

\section{V) Disparidad de los fallos constitucionales}

Uno de los obstáculos que también se presentó en este mecanismo de participación ciudadana es la disparidad de los fallos entre los tribunales administrativos y las altas corporaciones judiciales. En otras palabras, las discusiones que se suscitaron en relación con el ordenamiento y la planeación territorial respecto de la actividad minera tuvieron como consecuencia una serie de fallos judiciales contradictorios en sede del control de legalidad de los distintos tribunales administrativos y, aún más problemático, pronunciamientos discordantes entre las distintas secciones del Consejo de Estado y en la misma Corte Constitucional. Esta última se había decantado por una lectura más expansiva de la participación ciudadana y la autonomía territorial hasta su cambio de posición en 2018, lo que coincidió además con el cambio de magistrados.

Los jueces constitucionales tuvieron fallos disímiles. Mientras el Tribunal Administrativo de Antioquia negó en dos ocasiones el mecanismo para el municipio de Pueblorrico, el Tribunal del Tolima se mantuvo en su posición de que sí procedían las consultas. Esta posición fue avalada por el Consejo de Estado con fundamento en el análisis de la Constitución y del precedente de la Corte, el cual fue modificado posteriormente por el mismo Tribunal.

Como se evidencia, tanto las altas corporaciones judiciales como los tribunales han tenido pronunciamientos en sentidos contradictorios respecto de la procedibilidad del mecanismo. Frente a lo anterior, se debe tener en cuenta que, como bien lo ha expresado la jurisprudencia en sentencias como la SU-640 (1998), T-1009 (1999) y la C-836 (2001), la uniformidad en los fallos es la que permite materializar el derecho a la igualdad de los ciudadanos, la coherencia del sistema jurídico y el principio de buena fe y confianza legítima en las autoridades del Estado, entendida esta como la garantía de que esta actuará respetando sus actos anteriores.

En otras palabras, como bien lo plantea la sentencia hito C-836 (2001), el juez establece a través de sus pronunciamientos el alcance y ámbito de aplicación de los derechos y obligaciones de los administrados. En esa medida, si cada juez se pronuncia de forma distinta, ello deriva en un caos, toda vez que los ciudadanos no podrían desarrollar libremente sus actividades, en tanto se hace imposible inferir qué comportamientos o acciones están permitidas o protegidas, y en qué circunstancias contravienen el ordenamiento jurídico porque, frente a ciertas situaciones, siempre podrían estar contradiciendo una de las posibles interpretaciones de la ley.

19 Respecto de esta afirmación, téngase en cuenta que según cifras publicadas en el diario El Tiempo (2019), la protección al derecho fundamental de petición es el más exigido a través de la acción de tutela en el país, con 107.626 registros en entre enero y mayo de 2019. 
Dichos fallos contradictorios y la decisión de la Corte que cerró el debate y con ello determinó que las consultas no eran procedentes, implican una afectación a las garantías ciudadanas al menos en dos sentidos: i) vulneran el derecho a la igualdad de los ciudadanos con el agravante de que no hay posibilidad de controvertir las decisiones en otra instancia, ya que el procedimiento de la consulta popular solo establece una única decisión del juez; y ii) denota que en sede constitucional la Corte está incumpliendo con las cargas que se imponen para el cambio de precedente, lo cual no solo pone en riesgo las expectativas legítimas de aquellos ciudadanos que promovieron este mecanismo considerando la constitucionalidad del mismo y que luego se ven sorprendidos por un cambio del precedente, sino también de aquellos que realizaron los sufragios bajo la interpretación anterior.

Esto quiere decir que, si bien es claro que nuestro ordenamiento jurídico permite que existan decisiones contrarias de los jueces de instancia en atención a la autonomía judicial, en sede de lo que ha ocurrido con este mecanismo, resulta problemático la forma en que está diseñado el procedimiento, en tanto no se permite que la decisión del juez se controvierta ante otra instancia. Esto se ha visto aún más agravado por la reciente decisión de la Corte, la cual unificó su jurisprudencia desconociendo sus pronunciamientos anteriores e ignorando las propias exigencias que ella misma ha definido para el cambio de precedente al no referirse a las circunstancias fácticas o jurídicas que dieron lugar a un nuevo pronunciamiento en este materia ni expresar cuáles fueron las razones para desconocer o modificar sus providencias, lo cual constituye una de las irregularidades que implican una violación del debido proceso en conformidad con lo sostenido por esta misma corporación ${ }^{20}$.

\section{CONCLUSIONES}

La concesión de contratos para el desarrollo de la actividad minera en los territorios ha generado una serie de controversias y discusiones jurídicas entre los distintos entes territoriales en su intento por definir quién tiene la competencia en relación con la planificación territorial y, específicamente, respecto de los proyectos de exploración y explotación de hidrocarburos en las localidades. Tanto las autoridades municipales como los ciudadanos promovieron y dieron aplicación al mecanismo de la consulta popular, contemplado en la Ley 136 (1994) y en la Ley 1757 (2015) como medio para pronunciarse y decidir respecto de los usos del suelo de sus territorios.

En las entrevistas e información recolectada se pudo constatar que los ciudadanos no solo no tuvieron oportunidad de pronunciarse de manera previa a la concesión de los títulos mineros otorgados en sus territorios, sino que no los conocían mismos porque tampoco las autoridades locales (alcaldes y concejales) fueron notificadas o informadas de estas decisiones. Lo anterior contrasta con lo advertido por la Corte

20 Véase Sentencia C-621 (2015, p. 46). 
Constitucional, la cual ha determinado que el contenido de la participación ambiental no se agota con la simple socialización de los proyectos sobre el territorio, ya que esta implica el acceso a la información pública, la participación deliberativa de la comunidad y la existencia de mecanismos administrativos y judiciales para la defensa de dichos contenidos normativos. Estos asuntos distan de lo evidenciado en este trabajo, ya que en el ejercicio de este mecanismo existieron una serie de prácticas desplegadas desde lo institucional que reflejan la vulneración de las garantías democráticas que el Estado tiene la obligación de proteger.

El debate en relación con la participación en planeación territorial aún no ha sido resuelto, toda vez que la Corte definió en la Sentencia SU-095 (2018) (que declaró improcedentes las Consultas populares) que los procedimientos de licenciamiento ambiental, de concesión minera y de hidrocarburos presentan serias deficiencias en cuanto al acceso a la información y la participación. No obstante, (i) estos mecanismos se limitan a reuniones informativas con las comunidades; (ii) los resultados de dichas reuniones son simplemente insumos para la autoridad ambiental que no se encuentra obligada a tenerlos en consideración al momento de otorgar las autorizaciones ambientales y, por tanto, ello implica que (iii) ninguno es efectivo para llegar a acuerdos vinculantes y compromisos con las comunidades asentadas en las zonas de operación y que puedan ser afectadas por la misma.

Ahora, si bien es claro que la Corte Constitucional se pronunció en 2018 con respecto a esta materia, al definir que las consultas populares no son procedentes para oponerse a proyectos extractivos, aún quedan muchas preguntas por responder desde la disciplina jurídica. Para el momento en que el Tribunal Constitucional cambió de precedente, ya se habían realizado diez consultas en todo el país en las que participaron un total de 73.297 ciudadanos. Persisten, entonces, las siguientes preguntas: ¿Se están salvaguardando los derechos políticos de los ciudadanos o su efectividad está en entredicho? ¿Cómo se acompasan las recientes decisiones del alto Tribunal Constitucional con lo promulgado en la Constitución respecto de la democracia participativa?

\section{REFERENCIAS}

Abramovich V. y Courtis, C. (2003). Apuntes sobre la exigibilidad judicial de los derechos sociales. La protección judicial de los derechos sociales.

Agencia Nacional de Minería (S. f.). Catastro Minero. Consultado el 18 de octubre de 2019. http://www. cmc.gov.co:8080/CmcFrontEnd/consulta/index.cmc

Asamblea Nacional Constituyente (1991, 20 de julio). Constitución Política de Colombia de 1991. Gaceta Constitucional n. ${ }^{\circ}$ 116. https://www.funcionpublica.gov.co/eva/gestornormativo/norma.php?i=4125

Calle, H. (2019). Colombia: el segundo país donde más asesinan líderes ambientales. El Espectador. https://www.elespectador.com/colombia2020/pais/colombia-el-segundo-pais-donde-masasesinan-lideres-ambientales-articulo-873431 
Comisión Económica para América Latina y el Caribe (2018). Acuerdo Regional sobre el Acceso a la Información, la Participación Pública y el Acceso a la Justicia en Asuntos Ambientales en América Latina y el Caribe. Naciones Unidas.

Congreso de la República de Colombia (2015, 6 de julio). Ley Estatutaria 1757 de 2015. Diario oficial n. ${ }^{\circ}$ 49.565. http://www.secretariasenado.gov.co/senado/basedoc/ley_1757_2015.html

Congreso de la República de Colombia (1994, 31 de mayo). Ley 134 de 1994. Diario oficial n.o 41.373. http://www.secretariasenado.gov.co/senado/basedoc/ley_0134_1994.html

Consejo de Estado (2016, 23 de noviembre). Sentencia 11001-03-15-000-2016-03415-00/2016 (Carlos Enrique Monero Rubio, C. P.). http://relatoria.consejodeestado.gov.co/Document/?docid=11001 03-15-000-2016-03415-00(AC)

Corte Constitucional (2017, 15 de febrero). Auto 053/17 (Jorge Iván Palacio Palacio, M. S.). https://www. corteconstitucional.gov.co/relatoria/autos/2017/a053-17.htm

Corte Constitucional (2019, 13 de febrero). Sentencia C-053/19 (Cristina Pardo Schlesinger, M. P.). https://www.corteconstitucional.gov.co/relatoria/2019/C-053-19.htm

Corte Constitucional (2014, 05 de marzo). Sentencia C-123/14 (Alberto Rojas Ríos, M. P.). https://www. corteconstitucional.gov.co/relatoria/2014/c-123-14.htm

Corte Constitucional (2015, 08 de abril). Sentencia C-150/15 (Mauricio González Cuervo, M. P.). https:// www.corteconstitucional.gov.co/RELATORIA/2015/C-150-15.htm

Corte Constitucional (2002, 12 de marzo). Sentencia C-179/02 (Marco Gerardo Monroy Cabra, M. P.). https://www.corteconstitucional.gov.co/relatoria/2002/C-179-02.htm\#: :text $=$ Sentencia\%20 C\%2D 1 79\%2F02Etext $=$ En\%20lo\%20relativo\%20concretamente\%20a, textos\%20 legislativos\%2C\%20debe\%20tambi\%C3\%A9n\%20cumplirse

Corte Constitucional (1994, 14 de abril). Sentencia C-180/94 (Hernando Herrera Vergara, M. P). https:// www.corteconstitucional.gov.co/relatoria/1994/C-180-94.htm

Corte Constitucional (1994, 21 de julio). Sentencia C-336/94 (Carlos Gaviria Díaz, M. P.). https://www. corteconstitucional.gov.co/relatoria/1994/C-336-94.htm

Corte Constitucional (2013, 09 de julio). Sentencia C-551/03 (Eduardo Montealegre Lynett, M. P.). https://www.corteconstitucional.gov.co/relatoria/2003/C-551-03.htm

Corte Constitucional (2001, 09 de agosto). Sentencia C-836/2001 (Rodrigo Escobar Gil, M. P.). https:// www.corteconstitucional.gov.co/relatoria/2001/C-836-01.htm

Corte Constitucional (2018, 11 de octubre). Sentencia SU-095/2018 (Cristina Pardo Schlesinger, M. P.). https://www.corteconstitucional.gov.co/relatoria/2018/SU095 18.htm

Corte Constitucional (1998, 05 de noviembre). Sentencia SU-640/98 (Eduardo Cifuentes Muñoz, M. P.). https://www.corteconstitucional.gov.co/relatoria/1998/SU640-98.htm

Corte Constitucional (1999, 09 de diciembre). Sentencia T-1009/99 (Alejandro Martínez Caballero, M. P.). https://www.corteconstitucional.gov.co/relatoria/1999/T-1009-99. htm\#: : text=T\%2D1009\%2D99\%20Corte\%20Constitucional\%20de\%20Colombia\&text=En\%20 principio\%2C\%20no\%20hay\%20tutela,o\%20al\%20derecho\%20de\%20defensa

Corte Constitucional (2014, 22 de mayo). Sentencia T-294/14 (María Victoria Calle Correa, M. P.). https://www.corteconstitucional.gov.co/relatoria/2014/t-294-14.htm\#: :text=T\%2D294\%2D14\%20 
Corte\%20Constitucional\%20de\%20ColombiaEtext = Desde\%201998\%20Colombia\%20 adopt\%C3\%B3\%20una,(iv)\%20disposici\%C3\%B3n\%20final\%20controlada

Corte Constitucional (2012, 15 de mayo). Sentencia T-348/12 (Jorge Ignacio Pretelt Chaljub, M. P.). https://www.corteconstitucional.gov.co/relatoria/2012/T-348-12.htm

Corte Constitucional (2017, 30 de mayo). Sentencia T-361/17 (Alberto Rojas Ríos, M. P.). https://www. corteconstitucional.gov.co/relatoria/2017/t-361-17.htm

Corte Constitucional (2016, 19 de agosto). Sentencia T-445/16 (Jorge Iván Palacio Palacio, M. P.). https:// www.corteconstitucional.gov.co/relatoria/2016/t-445-16.htm

Corte Constitucional (2018, 30 de julio). Sentencia C-756/18 (Marco Gerardo Monroy Cabra, M. P.). https://www.corteconstitucional.gov.co/relatoria/2008/c-756-08.htm

Corte Constitucional (2017, 18 de octubre). Sentencia C-644/17 (Diana Fajardo Rivera, M. P.). https:// www.corteconstitucional.gov.co/relatoria/2017/C-644-17.htm

Corte Constitucional (2011, 04 de febrero). Sentencia T-047/11 (María Victoria Calle Correa, M. P.). https:// www.corteconstitucional.gov.co/relatoria/201 1/T-047 - 1 .htm\#: :text=T\%2D047\%2D 1 1\%20 Corte\%20Constitucional\%20de\%20ColombiaEtext =En\%20efecto\%2C\%20la\%20tutela\%20 debe,juez\%20conoce\%20el\%20derecho'\%2D.Etext=Lo\%20que\%20debe\%20examinar\%20 el,un\%20problema\%20de\%20derechos\%20fundamentales

Corte Constitucional (2015, 26 de agosto). Sentencia T-550/15 (Myriam Ávila Roldán, M. P.). https:// www.corteconstitucional.gov.co/relatoria/2015/t-550-15.htm\#: : :text=Los\%20derechos\%20 \%C3\%A9tnicos\%2C\%20como\%20la,de\%20sus\%20integrantes\%20individualmente\%20 considerados

Corte Constitucional (2015, 30 de septiembre). Sentencia C-621/15 (Jorge Ignacio Pretelt Chaljub, M. P.). https://www.corteconstitucional.gov.co/relatoria/2015/C-621 -15.htm

Echeverri, C. F. (2011). La participación ciudadana en Colombia: reflexiones desde la perspectiva constitucional y la normatividad estatutaria. Estudios de Derecho, 67(149), 61-86. https://revistas. udea.edu.co/index.php/red/article/view/8628

El Espectador (2017, 30 de noviembre). ¿Asfixiar las consultas populares? El Espectador. https://www. elespectador.com/opinion/editorial/asfixiar-las-consultas-populares-articulo-725992/

El Olfato (2016, 14 de septiembre). Las "advertencias" de la Procuraduría a los promotores de consultas mineras en el Tolima. https://www.elolfato.com/las-advertencias-de-la-procuraduria-a-los-promotores-deconsultas-mineras-en-el-tolima

El Tiempo (2017, 1 de octubre). Córdoba, Quindío, tendrá su consulta contra la minería en diciembre. https:// www.eltiempo.com/colombia/otras-ciudades/consulta-contra-mineria-en-cordoba-quindio-136504

El Tiempo (2019, 8 de agosto). En los primeros 5 meses del año se interpusieron 280 mil tutelas. https://www. eltiempo.com/justicia/cortes/balance-de-tutelas-por-salud-y-derecho-de-peticion-en-el-2019segun-corte-constitucional-398342

Galeano, E. (2004). Estrategias de investigación social cualitativa: el giro en la mirada. La Carreta.

Gobernación de Antioquia (2018, 29 abril). Mapa minero de Antioquia. Consultado el 17 de octubre de 2019. https://issuu.com/gobantioquia/docs/mapa_minero_de_antioquia

Goffman, E. (1963). Estigma: la identidad deteriorada. Amorrortu Editores 
González, J. (2018). En 2017 se realizaron 7 consultas populares y hay 54 pendientes. https://www.larepublica. co/especiales/minas-y-energia/en-2017-se-realizaron-7-consultas-populares-y-hay-54pendientes-2613185

Gutiérrez, C. (2014, 13 de marzo). Mensaje de Procuraduría asusta a alcaldes que rechazan minería. El Espectador https://www.elespectador.com/noticias/medio-ambiente/mensaje-de-procuraduria-asusta-alcaldesrechazan-mineri-articulo-480724

Güiza, L. y Rodríguez, C. (2015). El papel de las autoridades territoriales en la definición de zonas exclusión o restricción minera. Vniversitas, (131), 323-362.

Hincapié, S. (2017). Extractivismo, consultas populares y derechos políticos ¿El renacimiento de la democracia local en Colombia? Reflexión Política, 19(37), 86-99.

López, D. (2006). El derecho de los jueces: obligatoriedad del precedente constitucional, análisis de sentencias y líneas jurisprudenciales y teoría del derecho judicial. Legis.

Muñoz, L. (2016). Derechos de acceso en asuntos ambientales en Colombia: hacia el desarrollo de una actividad minera respetuosa del entorno y las comunidades.

Naciones Unidas. (1992). Declaración de Río sobre Medio Ambiente y Desarrollo. Río de Janeiro. https://www. un.org/spanish/esa/sustdev/agenda2 1/riodeclaration.htm

Naciones Unidas. (1997). Protocolo de Kyoto de la Convención Marco de Las Naciones Unidas sobre el Cambio Climático. https://unfccc.int/resource/docs/convkp/kpspan.pdf

Naciones Unidas. (2015). Acuerdo de París. http://unfccc. int/resource/docs/2015/cop21/spa/109s.pdf

Naciones Unidas. (1972). Declaración de Estocolmo sobre el medio ambiente humano. http://www.ordenjuridico. gob.mx/TratInt/Derechos\%20Humanos/INST\%2005.pdf

Organización de los Estados Americanos (2001). Carta Democrática Interamericana. http://www.oas.org/ OASpage/esp/Documentos/Carta_Democratica.htm

Organización de los Estados Americanos (1978). Convención Americana sobre Derechos Humanos. https:// www.oas.org/dil/esp/tratados_b-32_convencion_americana_sobre_derechos_humanos.htm

Organización Internacional Del Trabajo (1989). Convenio 169 sobre pueblos indígenas y tribales en países independientes. https://www.ilo.org/wcmsp5/groups/public/- -americas/- -ro-lima/documents/ publication/wcms_345065.pdf

Osorio, L. G. y Torres, Y. E. (2017). ¿Prohibir la minería desde lo local? Autonomía territorial en la regulación de los usos del suelo y protección del medio ambiente. A propósito de los acuerdos municipales de los municipios Caicedo, Cañasgordas, Jardín, Támesis y Urrao, Antioquia, 2012-2013.

Quintero, S. P. D., Sánchez, F. P. G., Acevedo, N. A. C. y Monsalve, S. M. M. (2018). Investigación en el saber jurídico. Universidad de Antioquia.

Ramírez, A. (2016). Participación ciudadana e interpretación de la constitución. Análisis de la jurisprudencia de la Corte Constitucional colombiana en materia de democracia participativa. Revista IUS, 10(37), 171-192.

Rodríguez, G. y Muñoz, L. (2009). La participación en la gestión ambiental: un reto para el nuevo milenio. Universidad del Rosario.

Rodríguez, G. (2014). De la consulta previa al consentimiento libre, previo e informado a pueblos indígenas en Colombia. Universidad del Rosario, Cooperación Alemana. 
Rolón, M. (2017, 24 de marzo). Así votará Cajamarca su consulta popular. El Espectador. https://www. elespectador.com/noticias/medio-ambiente/asi-votara-cajamarca-su-consulta-popular/

Rubiano, M. P. (2018, 20 de mayo). Freno financiero a las consultas populares. El Espectador. https:// www.elespectador.com/noticias/medio-ambiente/freno-financiero-las-consultas-popularesarticulo-789571

Sostenibilidad Semana. (2017, 22 de marzo). Cajamarca se juega su futuro en la consulta popular del domingo. https://sostenibilidad.semana.com/medio-ambiente/articulo/parques-nacionales-figurasestrategicas-de-conservacion-sandra-vilardy/51179

Velásquez, F. y González, E. (2003). ¿Qué ha pasado con la participación ciudadana en Colombia? Fundación Corona.

Tierra Digna. (2019). 10 principios a tener en cuenta para un ordenamiento socio ambiental del territorio desde el punto de vista del derecho a la participación (manuscrito no publicado). 